\title{
PAROXYSMAL HEART BLOCK AND VENTRICULAR STANDSTILL
}

\author{
BY \\ J. STEWART LAWRENCE AND G. WILSON FORBES \\ From Haymeads Emergency Hospital \\ Received August 10, 1943
}

In auriculo-ventricular block the degree of impairment of conductivity is often found to be inconstant. Even at a time when the rhythm appears clinically to be normal, however, a cardiogram will usually show prolongation of the $\mathrm{P}-\mathrm{R}$ interval. Only rarely is the conduction normal between the attacks, and the term " paroxysmal heart block" may then appropriately be applied. Reports of 18 such cases have been found, 7 of which had periods of ventricular standstill also; in addition, we found 3 cases of paroxysmal ventricular standstill without heart block (see Starling and Lewis, infra).

Hay (1906) described a case in which occasional ventricular beats were dropped, despite regular auricular contractions as shown by the polygraph and unimpaired conduction in the remaining beats; he suggested a depression of ventricular excitability as the cause. His patient was a man of 65 with hypertensive heart disease, and partial heart block had been present in a previous tracing. Gossage (1909) described a similar condition in a woman of 71 - with hypertension, and considered it an intermittent form of heart block. In a case recorded by Macintosh and Falconer (1910), a man of 74 had periods of ventricular standstill with Stokes-Adams seizures, during which the auricular rate gradually accelerated, slowing again when the ventricular contractions returned; they were abolished by atropine. Periods of complete A-V block and also of high-grade partial block with a slow irregular ventricular beat were encountered at times. Between attacks, the a-c interval was normal.

Starling (1921) reported the occurrence of periodic ventricular standstill with Stokes-Adams attacks in a man of 51 with a normal-sized heart and a blood pressure of 160/110. Conduction was unimpaired in the intervals. Swallowing used to bring on an attack, but not if atropine had been given during the previous hour. Complete heart block finally supervened. RussellWells and Wiltshire (1922) described a male, aged 58, with intermittent complete heart block. The conduction was normal in the intervals. Infective endocarditis was found post-mortem and calcification in the region of the A-V bundle. In the case of Gage and Pardee (1925), a man of 59 with arteriosclerosis, there was intermittent complete block and at other times intermittent ventricular standstill. Conduction was normal in the intervals. Atropine was without effect but adrenaline was followed by ventricular tachycardia, ventricular standstill, and death. Post-mortem, the mitral valve was found to be calcified. Lewis (1925) mentions two cases of intermittent ventricular standstill in patients with normal A-V conduction, in one of which the fibres of the bundle were found to be separated by large venous sinuses. Yater and Williams (1928) described a man of 74 with arteriosclerosis who had periods of normal rhythm alternating with $\dot{2}: 1$ heart block, complete heart block, and ventricular standstill ; post-mortem, there was calcification in the interventricular septum at the junction of its membranous and muscular parts, and invasion of the bundle of His by fibrous tissue. In the case recorded by Wolferth and McMillan (1928), a woman aged 48, periods of partial and complete block were interspersed with normal rhythm during which conduction was unimpaired. Even during phases of partial block, the P-R interval was normal. Atropine 
and amyl nitrite increased the auricular rate and the degree of heart block. Arteriosclerosis was present, and the bundle of His was infiltrated by fibrous tissue and round cells.

The case of Carter and McEachern (1931), a man of 63 with hypertensive heart disease, also had a normal conduction time between attacks of complete heart block-attacks that were unaffected by atropine, exercise, or oxygen. Sachs and Traynor's patient (1933), aged 43, had Stokes-Adams attacks during which complete heart block with a very slow idioventricular rhythm was found; during the intervals the P-R interval was normal; atropine had no effect, but the attacks cleared up following recovery from empyema; there was no evidence of disease of heart or arteries. The patient described by Weiss and Ferris (1934) was a man of 64 with moderate arteriosclerosis and a diverticulum in the œsophagus. Fainting attacks occurred when he swallowed and were found to be due to complete heart block. When a balloon was passed into it and distended, prolongation of the $P-R$ interval was produced, and then complete A-V block, which could be prevented by atropine, or by the injection of procaine into the vagus in the neck so that it was evidently a vagal reflex. Comeau (1937) reported a case of paroxysmal heart block in a woman of 76; the P-R interval was normal between the attacks and these were not abolished by atropine: permanent heart block eventually supervened. A similar case in a man, aged 57 , went on to permanent block after two-and-a-half months. Gilchrist (1937) reported two cases of intermittent heart block, both in elderly persons; normal rhythm without delayed conduction was usually followed by ventricular standstill and this by a period of complete A-V block : both patients were benefited by ephedrine. Parkinson, Papp, and Evans (1941) reviewing the subject of Stokes-Adams attacks record the case of a male, aged 43, in whom periods of ventricular standstill started with a delayed auricular beat not followed by a ventricular complex and ended with an ectopic beat $0 \cdot 1 \mathrm{sec}$. after $\mathrm{P}$, after which sinus rhythm was resumed without impairment of conduction. Paroxysms lasted 5-20 seconds. There were also occasional periods of complete block. He showed no other evidence of cardiac abnormality and attacks ceased after a month. Of 38 cases of partial heart block with dropped beats recorded by Campbell (1943), 3 had paroxysmal block. One, a woman aged 66 with hypertensive heart disease, had phases of sinus rhythm, dropped beats and complete heart block; the P-R interval was 0.21 sec., which is within normal limits according to Chamberlain and Hay (1939). One in his series had at one time a $2: 1$ heart block with a P-R interval of $0 \cdot 19$ sec. or less, a man of 55 with congestive failure; the third, a woman aged 25 , was rather different as the heart block was temporary and due to active rheumatic carditis. [Three others have been added in the paper that follows this-Cases 101, 106, and 115 (Campbell, 1944).]

\section{OBSERVATIONS}

Our own case, a retired gardener, aged 71, stated that he had been in good health till four years previously when his ribs were injured in an accident. He noticed some dyspnœa on exertion after this but returned to work. Six months later, however, the dyspnœa was so bad that he had to give up his work and had not returned since. Three years ago he had attacks of nausea, relieved by food; and a few weeks later, attacks that started with a tingling in the legs, passing up to the head, and then severe pain in the head; he would fall forward, dazed but not unconscious. These attacks recurred frequently and two years ago during a severe one he lost his power of speech and had convulsive movements of the limbs. This was the first occasion of his admission to hospital. He was found to have a pulse rate of 35-40 with occasional coupled beats. After an attack of unconsciousness, stated to have lasted 4-5 minutes, his pulse rate rose to 70 per minute. No cardiogram was taken at that time. After discharge from hospital, he continued to have attacks several times a day with occasional remissions lasting a few days. Latterly the attacks have started with pain in the left side followed by palpitation, slow at first but accelerating (probably the auricular contractions). $\mathrm{He}$ had to sit down and usually became unconscious for a few seconds; sometimes uncon- 
sciousness was more rapid and he fell to the ground. He was readmitted in September, 1942. He was found to be of plethoric type. The pulse was slow and for the most part irregular, varying from 24-56 per minute. The auricular wave could be seen in the neck beating regularly at 80 a minute so that the ventricles on these occasions appeared to be responding to every third beat. Sometimes every beat of the auricles was followed by a ventricular contraction for a minute or so and this would alternate with periods of ventricular asystole during as much as nine consecutive beats of the auricle. During these periods of ventricular asystole, the patient became pale, anxious, and restless, and the auricular waves in the neck gradually became more rapid and forcible. When the ventricles again started to beat, the face immediately flushed, the patient's anxiety and restlessness passed off, and the auricles resumed their previous rate.

The maximum blood pressure was $180 / 80 \mathrm{~mm}$. The arteries did not appear thickened. There was a systolic murmur, maximal at the apex. No abnormal signs were found in the remainder of the physical examination, apart from absence of the knee jerks and a tremor of senile type in the hands. The urine showed no abnormality. The blood W.R. was negative.

Fluoroscopy showed the heart to be of normal shape and size. On the first occasion the ventricles were responding to every auricular beat, but on a second occasion periods of ventricular asystole were observed and the increasing speed and force of the auricular contractions at these times was confirmed.

Fig. 1, taken on admission, showed an unusual rhythm. There was for the most part, complete dissociation between auricles and ventricles, the auricles beating at 70 a minute, the

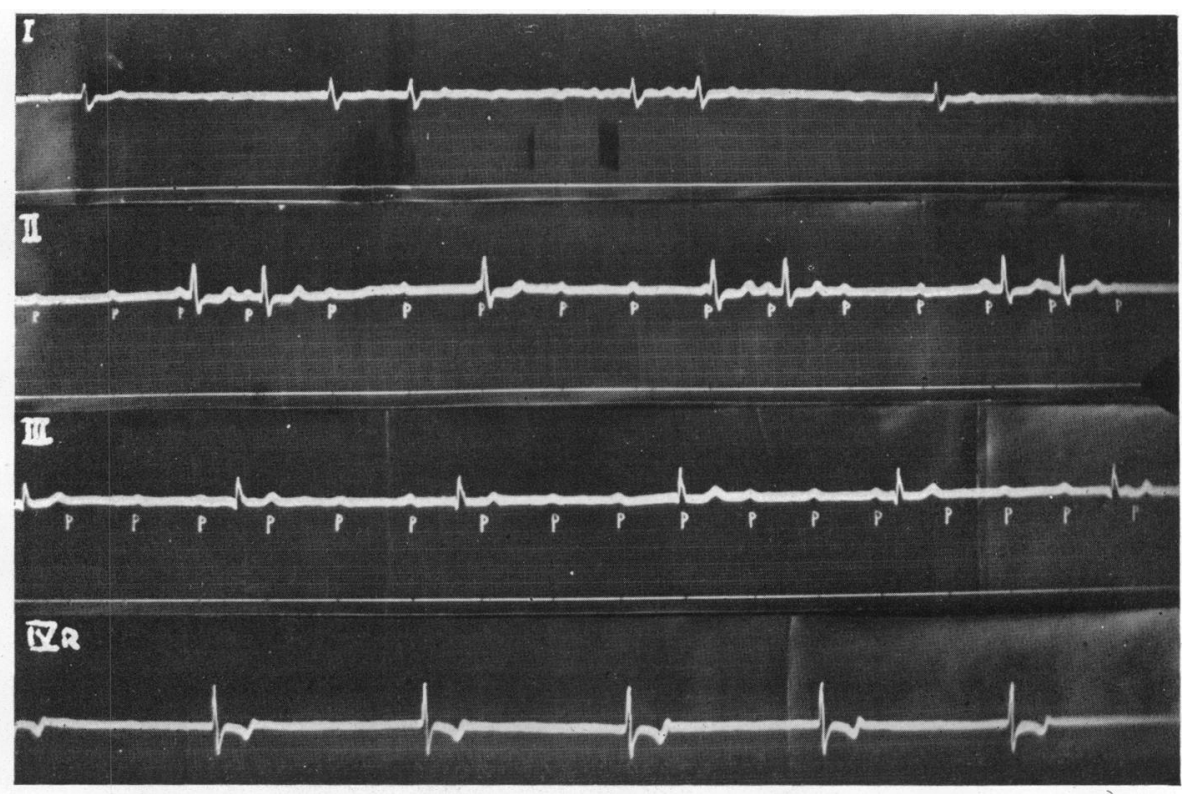

FIG. 1.-On admission. There is complete heart block except when a $P$ wave follows immediately on a ventricular complex when the impulse is conducted normally.

ventricles at 23. At irregular intervals the slow idioventricular rhythm was interrupted by an added ventricular beat which always followed a $P$ wave at an interval of $0.2 \mathrm{sec}$. These added beats occurred only when the $P$ wave happened to come soon after one of the ventricular complexes. The picture therefore was one of complete heart block, with the ventricles responding to an occasional auricular contraction with a normal conduction time. The ventricular complexes were normal apart from slurring of S I and a biphasic T IV.

After his admission, when no drugs were given, the pulse continued to vary as already described and Stokes-Adams attacks were numerous. Ephedrine was then administered at 
4-hourly intervals in increasing doses from 0.5-2 grains. No alteration occurred in the pulse and attacks continued to be numerous. The treatment had to be abandoned in a few days, as it was found to produce retention of urine (the prostate was much enlarged).

Digitalis was then given, the initial dose being half a grain of the powdered leaf, t.i.d., rising to 2.5 grains, t.i.d. Stokes-Adams attacks became less numerous and the pulse, though varying between 20 and 56 a minute, showed less irregularity. Fig. 2 showed that the auricular rate was slower $(50)$ and that, at the time of the tracing, the ventricles were responding to every second beat, the P-R interval being of normal duration $(0 \cdot 18 \mathrm{sec}$.). Numerous ventricular extrasystoles were present. The $P$ wave was low in all leads but best seen in the right pectoral lead (right arm lead to right arm, chest lead applied at the fourth intercostal space just to the right of the sternum). In the limb leads the QRS complexes had become widened,

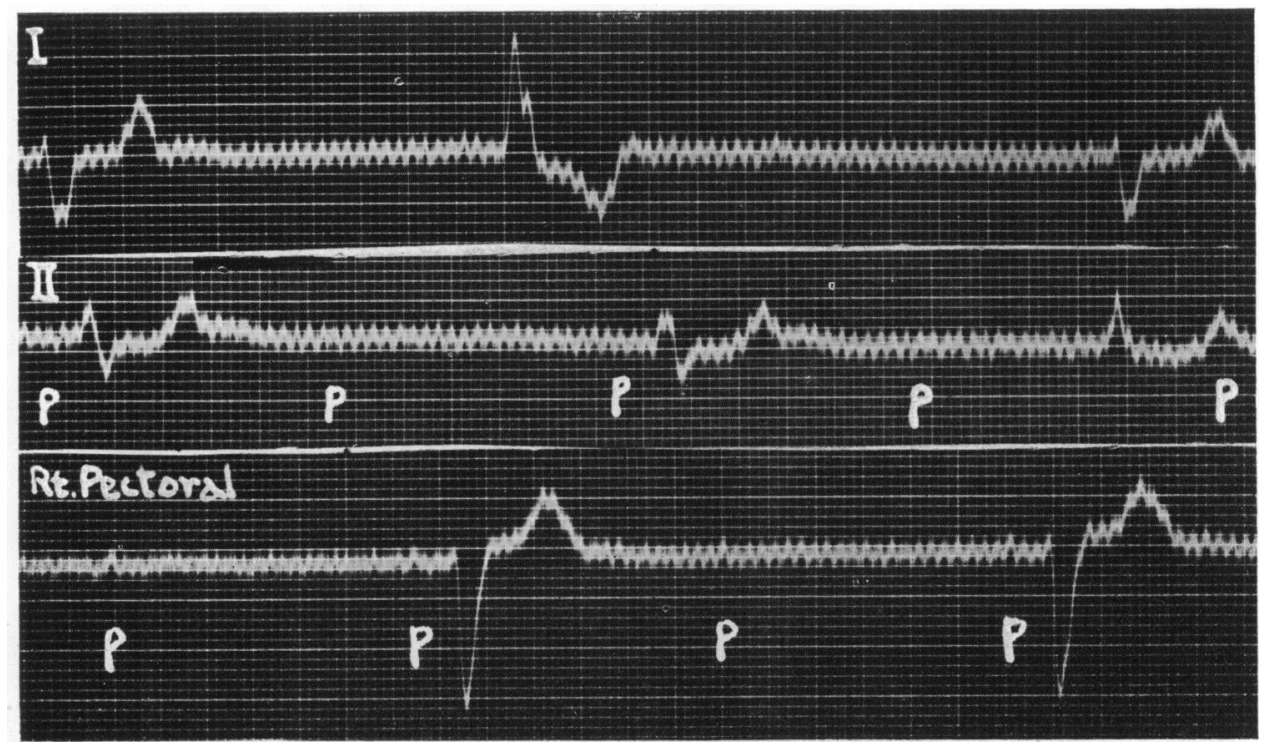

FIG. 2.-The patient is receiving $7 \cdot 5$ grains of digitalis powdered leaf daily. The auricular rate has become slower and the ventricles are responding to alternate auricular beats.

$\mathrm{R} I$ and R II diminished, and S I increased. On another occasion, when the patient was still having digitalis, (Fig. 3), he showed a normal sinus rhythm punctuated by periods of ventricular asystole, varying in duration from 6-11 seconds: the auricular rate was 45 and the P-R interval $0.2 \mathrm{sec}$. During the phases of ventricular asystole the auricular rate steadily increased up to about 60 a minute and then when normal rhythm had returned slowed down to 45 again; the first ventricular systole was not accurately related to the preceding $P$ wave, the $P-R$ interval being 0.3-0.48 sec. and was therefore presumably an idioventricular beat. It was sometimes followed by a missed beat or a ventricular extrasystole before a normal sequence was re-established. As this type of rhythm had been noted before giving digitalis, it was evidently not due to the drug. The inversion of QRST in this and subsequent records could not be accounted for, except possibly by alteration of posture.

Belladonna, 20 minims, t.i.d., resulted in more frequent Stokes-Adams attacks. The auricular rate rose to 90 and, at the time of the cardiogram, the ventricles were responding to alternate stimuli. Such phases were unfortunately very transient and infrequent.

Barium chloride, 1 grain 4-hourly, was without effect. Adrenaline hypodermically merely produced retention of urine.

At this stage it was felt that, as belladonna and ephedrine had not affected the dysrhythmia, it was unlikely to be due to a vagal reflex as in the case reported by Weiss and Ferris (1934). A spasm or partial occlusion of one of the small arteries supplying the bundle of His seemed a 


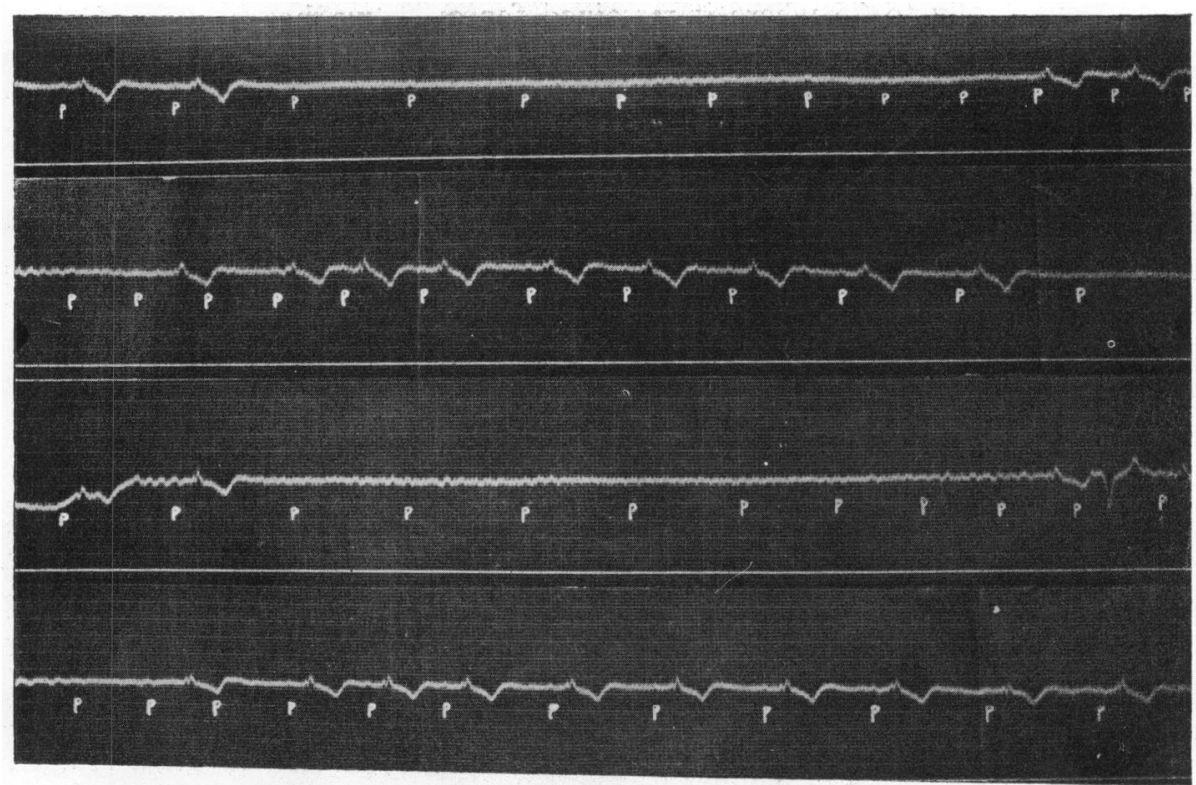

FIG. 3.-Paroxysmal ventricular standstill alternating with normal rhythm (right pectoral lead).

possible cause, so amyl nitrite was next administered. Thirty seconds after inhaling a 2-minim ampoule, the pulse, which before had been beating irregularly at 28 , rose to a rate of 70 a minute and became regular, remaining so for the next half hour. In Fig. 4, taken just after the inhalation of amyl nitrite, auricles and ventricles are both beating at 70 a minute, the P-R interval being $0 \cdot 16-0.2 \mathrm{sec}$. Just before this tracing, intermittent ventricular standstill had

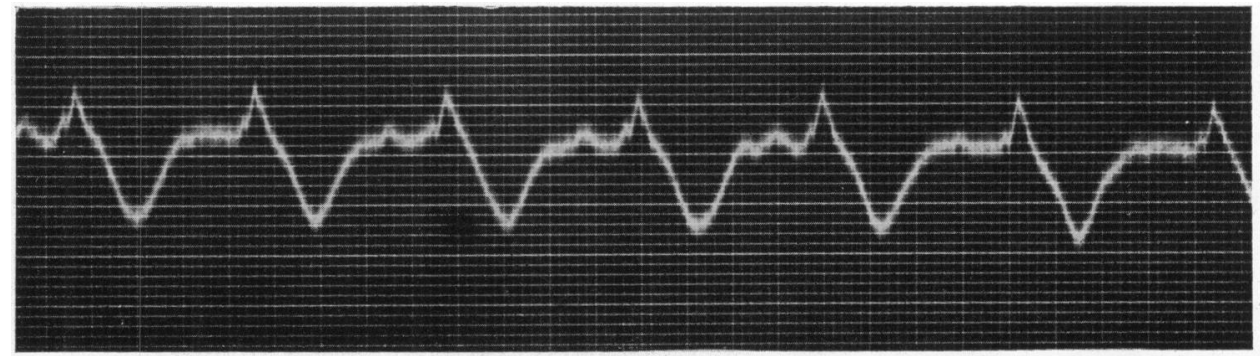

FIG. 4.-Immediately after the inhalation of amyl nitrite. A normal sinus rhythm, rate 70 a minute. The inverted $T$ wave was of similar magnitude before the inhalation (see Fig. 3) (right pectoral lead).

been present as in Fig. 3. Unfortunately glyceryl trinitrini and sodium nitrite were without effect, but by inhalations of amyl nitrite whenever minor attacks began to appear, it was found possible to keep the patient fairly well stabilized. To facilitate this and to avoid the expense of numerous glass capsules, a small wide-mouthed, glass-stoppered bottle was filled loosely with cotton wool and this was soaked with amyl nitrite. The patient kept this by him and inhaled from it whenever the periods of ventricular asystole became troublesome. He soon learned how much to inhale in order to abort the attacks, but no harm resulted if he continued to inhale till the pulse became regular and rapid.

To test further the theory of coronary spasm, the effect of other substances acting on the coronary arteries was studied. Adrenaline dilates the coronary arteries, but also by raising the blood pressure stimulates the vagi through the carotid sinus and aortic nerves (Wright, 1930), so producing an opposing constrictor effect. If the vagus is blocked by atropine, this constrictor effect is avoided and dilatation occurs. Atropine and adrenaline in doses of $0.5 \mathrm{mg}$. of each were accordingly injected subcutaneously. The pulse rate rose from 30 to 66 in 25 
minutes and eventually to 75 where it remained for over two hours. Fig. 5 showed the auricles and ventricles beating normally at 75 a minute, with a $P-R$ interval of $0.2 \mathrm{sec}$. Ventri-

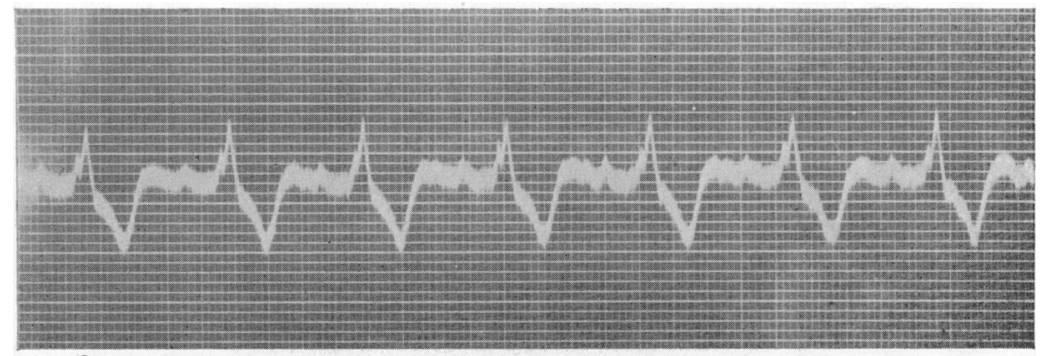

FIG: 5.-After administration of adrenaline and atropine. A normal sinus rhythm is present, rate 75 a minute (right pectoral lead).

cular extrasystoles were numerous at first but these had disappeared after one-and-a-half hours, leaving a pure sinus rhythm.

Both lack of oxygen and excess of carbon dioxide cause dilatation of the coronary arteries. The former, however, does not increase the oxygen consumption of the heart muscle, as the increased coronary flow merely keeps pace with the diminished oxygen saturation (Hilton and Eichholtz, 1925). Thus only excess of carbon dioxide without lack of oxygen will increase the oxygen available to the myocardium. Lack of oxygen was produced in this case by breathing nitrogen through a B.L.B. mask till cyanosis appeared. In Fig. 6, obtained at this

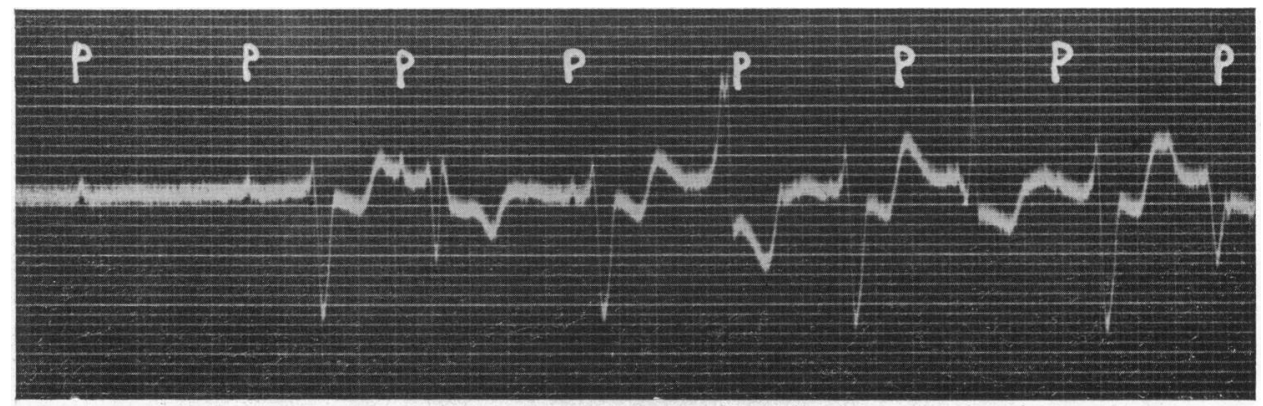

FIG. 6.-Record taken during a period of induced lack of oxygen. There is complete A-V block and ventricular contractions are arising from a number of different foci (right pectoral lead).

time, there is complete A-V block with ventricular complexes arising from a number of different foci.

Carbon dioxide was administered at a concentration of 5 per cent in oxygen. It resulted in the ventricles responding to alternate beats of the auricle, a ventricular extrasystole following each normal beat; the P-R interval was 0.2 sec.

Freedberg, Riseman, and Spiegl (1941) have shown that quinidine reduces the tendency to effort pain in angina pectoris, and prevents the cardiographic changes usually associated with the attack. When this drug was given to our patient in doses of 3 grains 3-hourly, the pulse became, for the most part regular at a rate of 30-32 a minute with occasional more rapid periods (62-70). The cardiogram showed complete heart block, the auricles beating at 75 , the ventricles at 33; numerous extrasystoles were present at the time of the record. No Stokes-Adams attacks occurred during the first week of this treatment but during the second week occasional severe attacks occurred. During one of these, the ventricular contractions failed to return and the patient died.

Post-mortem examination showed no gross abnormality in the heart. Small atheromatous plaques were scattered throughout the coronary arteries but these were not sufficient to 
obstruct the lumen at any point. No pathological change was evident in the A-V bundle or in any other part of the myocardium.

\section{Discussion}

Of the 22 cases reviewed in this paper, 8 had intermittent heart block, 5 had intermittent ventricular standstill, and 9 exhibited at different times both phenomena. In all these cases conduction through the bundle of His was normal between the attacks, even when, as in 4 of the cases of ventricular standstill, only a single beat was missed at a time. These latter cases could be differentiated from partial heart block only by the normal $P-R$ interval in intervening beats. In 4 of the cases, however, transient periods of partial block were noted in addition to periods of complete heart block and ventricular standstill.

The effect of drugs was not uniform. Atropine abolished the attacks temporarily in 4; ephedrine was effective in 2, adrenaline in 1 case. In 1 , injection of procaine into the vagus abolished the attacks temporarily. The condition was aggravated by both atropine and amyl nitrite in 1, the only other case in which amyl nitrite appears to have been tried.

Of the patients 13 were males and 5 females, and in 4 the sex was not given. The ages ranged from 25 to 76, the average being 59. Calcification or fibrosis was found in the bundle of His in 4, and large venous sinuses in 1 case. Hypertension or arteriosclerosis was present in 10 ; in 1 , a diverticulum of the œsophagus was shown to be the cause.

The frequency with which intermittent heart block and intermittent ventricular standstill, though both very rare, are associated in the same patient indicates a common cause. An intermittent depression of excitability of the ventricular muscle, as suggested by Hay, explains the periods of ventricular asystole but not the periods of partial or complete block. Moreover, digitalis, which increases the excitability of the heart muscle, does not abolish the periods of ventricular asystole, but seems rather to lengthen them; and quinidine, which depresses the excitability of the heart muscle, does not render them more frequent though possibly more prolonged.

Spasm or partial occlusion of an artery supplying the conducting bundle would account for both the intermittent block and the ventricular standstill, assuming that the bundle fibres were capable of immediate recovery following the short periods of anoxæmia so produced. In favour of this hypothesis, hypertension or arteriosclerosis was observed in half the cases, and all except one were in the latter half of life. Further, in the authors' case, amyl nitrite abolished the attacks in 30 seconds (amyl nitrite takes 30-60 seconds to produce its full dilator effect on the arterioles); atropine and adrenaline together were effective, but not separately; inhalation of carbon dioxide reduced the degree of heart block; and during " complete" heart block, an auricular wave falling immediately after ventricular systole would be conducted through the A-V bundle and give rise to an added ventricular beat. It is in early diastole that the coronary flow reaches its maximum according to Anrep (1926) (for record see Fig. 1). Finally, prolonged ventricular asystole was always followed, after one or two idioventricular contractions, by a phase of normal sinus rhythm. This may be explained as follows. Ischæmia of the A-V bundle due to arterial spasm or partial occlusion blocks the passage of the contraction wave, and ventricular standstill results. This gives rise to a rapidly increasing cerebral and coronary anoxæmia and an accumulation of carbon dioxide in the blood. These three factors all have the effect of dilating the coronary arteries (Hilton and Eichholtz, 1925; Anrep and Segall, 1926), but the coronary anoxæmia still impairs the function of the bundle, and impulses continue to be blocked. Eventually idioventricular contractions appear as in commencing complete heart block. This causes a surge of oxygenated blood through the now widely dilated coronary arteries, thus restoring the function of the bundle. Cerebral anoxæmia and the excess of carbon dioxide are relieved and the tone of the coronary arteries returns so repeating the cycle.

It is unlikely that ischæmia of the A-V bundle is the mechanism responsible for all cases of 
paroxysmal heart block and ventricular standstill. A simple inhibitory action of the vagus on the A-V bundle may have been the cause in those cases relieved by atropine, especially the case of Weiss and Ferris in which distension of the esophageal diverticulum produced an attack, but, as the vagus contains vasoconstrictor fibres to the coronary arteries, ischæmia may have played a part here also.

\section{SUMMARY}

A case is described showing periods of intermittent heart block and occasionally a phasic ventricular standstill. Conduction was normal in the intervening stages.

Eighteen reported cases of this type are reviewed.

It is suggested that arterial spasm or partial arterial occlusion is the main factor in the majority of these cases.

It was found possible to control the attacks by inhalations of amyl nitrite.

We wish to express our thanks to Dr. R. A. Hill, Medical Superintendent of Haymeads Emergency Hospital for facilities granted.

\section{REFERENCES}

Anrep, G. V. (1926). Physiol. Rev., 6, 596. , and Segall, H. N. (1926). Heart, 13, 239.

Campbell, M. (1943). Brit. Heart J., 5, 55. (1944). Ibid., 6, 69.

Carter, E. P., and McEarchern, D. (1931). Bull. John Hopkins Hosp., 49, 337.

Chamberlain, E. N., and Hay, J. D. (1939). Brit. Heart J., 1, 105.

Comeau, W. J. (1937). Amer. J. med. Sci., 104, 43.

Gage, L. J., and Pardee, H. E. B. (1925), ibid., 169, 656.

Gilchrist, A. R. (1937). Brit. med. J., 1, 203.

Gossage, A. M. (1909). Heart, 1, 283.

Hay, J. (1906). Lancet, 1, 139.

Hilton, R., and Eichholtz, F. (1925). J. Physiol., 59, 413.

Lewis, T. (1925). The Mechanism and Graphic Registration of the Heart beat, 3rd. ed., London, 421.

McIntosh, A. W., and Falconer, A. W. (1910). Heart, 2, 222.

Parkinson, J., Papp, C., and Evans, W. (1941). Brit. Heart J., 3, 171.

Russell-Wells, S., and Wiltshire, H. W. (1922). Lancet, 1, 984.

Sachs, A., and Traynor, R. L. (1933). Amer. Heart J., 9, 267.

Starling, H. J. (1921). Heart, 8, 31 .

Weiss, S., and Ferris, E. B. (1934). Arch. intern. Med., 54, 931.

Wolferth, C. C., and McMillan, T. M. (1928-9). Amer. Heart J., 4, 521.

Wright, S. (1930). J. Physiol., quoted by Wright (1940), Applied Physiology, 7th. ed., 193, London.

Yater, W. M., and Willius, F. A. (1928-9). Amer. Hearl J., 4, 280. 